\title{
Population structure of the wood decay fungus Fomitopsis pinicola
}

\author{
NILS HÖGBERG* $\uparrow$, OTTMAR HOLDENRIEDER $\$$ \& JAN STENLID† \\ $\dagger$ Swedish University of Agricultural Sciences, Department of Forest Mycology and Pathology, Box 7026, \\ Ulls väg 26a, S-750 07 Uppsala, Sweden and $\$$ Section of Forest Pathology and Dendrology, Department of Forest \\ and Wood Sciences, Federal Institute of Technology, ETH-Zentrum, Raemistr. 101, CH-8092 Zurich, Switzerland
}

\begin{abstract}
Three populations of the wood decay fungus Fomitopsis pinicola, one from each of three countries (Sweden, Russia and Lithuania), were studied by means of arbitrary primed PCR. The genetic structure of the populations was assessed by inferring the genotype of the genets by studying the haplotypes of several single-spore isolates from one sporocarp for each individual. Heterozygotes could therefore be detected with a dominant genetic marker. The amplified band and the null allele of all loci segregated in a way that was in agreement with a 50:50 ratio. Genetic analysis showed that the total population as well as the subpopulations had heterozygote frequencies in agreement with Hardy-Weinberg expectations. No population differentiation was detected in spite of large geographical distances among the populations studied. We also compared the methods of somatic incompatibility and AP-PCR in terms of their value in detecting fungal genets. This was tested for a sample of dikaryotic mycelia from Switzerland. For the tested material the two methods gave congruent results.
\end{abstract}

Keywords: AP-PCR, basidiomycetes, Fomitopsis pinicola, population differentiation.

\section{Introduction}

Fomitopsis pinicola (Swartz: Fr.) Karst. is a saprotrophic polypore with a worldwide distribution in temperate and boreal forests. It attacks both conifers and hardwoods causing a cubical brown-rot (Ryvarden \& Gilbertsson, 1993). The fruiting bodies are perennial (Ryvarden \& Gilbertsson, 1993). The sexual system is heterothallic (Mounce, 1930), meaning that two haploid mycelia are only able to form a dikaryotic mycelium and complete the sexual cycle if they have different alleles at the mating-type locus.

The recognition of an individual genet of a fungus requires special methods because the mycelium grows inside the substrate and intraspecific variation in morphology is too small to allow discrimination after cultivation. Individual basidiomycete genets can be identified either by means of somatic incompatibility responses or based on the distribution of genetic markers. Somatic incompatibility can be defined as the rejection of nonself mycelia following hyphal anastomosis (Worrall, 1997). Fomitopsis pinicola was the first basidiomycete to be studied by means of somatic incompatibility (Mounce, 1929). Although variable,

*Correspondence. E-mail: nils.hogberg@uclink4.berkeley.edu the somatic incompatibility reactions in this fungus are easily scored and have been used to study individual delimitation (Mounce, 1929). Somatic incompatibility has since then been a widely used method for analysing the population structure of basidiomycetes (Worrall, 1997).

The distribution of genets can also be inferred from genetic markers, which offer an important advantage in that not only can the number of the individuals in the population be scored, but the relatedness among them can also be assessed. For genetic studies of diploid or heterokaryotic organisms codominant markers are preferred, because both alleles at a locus can be scored and thus the genotype and the gene frequencies can be determined. In basidiomycetes, gene frequencies of dominant markers can be inferred by studying their segregation into haploid offspring. This technique has been used in studies of the biology of Cronartium ribicola Fisch., the white pine blister rust (Gitzendanner et al., 1996).

Here we present the genetic structure of populations over a wide geographical range in Europe to address questions regarding the genetic diversity of $F$. pinicola. In an earlier study, population differentiation among populations in Sweden and Finland was found to be very low (Högberg et al., 1995). In this study we also 
wanted to determine whether somatic incompatibility in $F$. pinicola agrees with the phenotypes obtained with AP-PCR (Welsh \& McLelland, 1990). This was undertaken using material sampled in Trun, Switzerland. After a storm a large gap was created in the canopy of Norway spruce and the broken trees became infected with $F$. pinicola; we investigated whether the population structure of this founding event was associated with low genetic diversity.

\section{Materials and methods}

\section{Study sites}

All material was sampled in forests containing Norway spruce Picea abies (L.) Karst., which was the dominating species, and Scots pine Pinus sylvestris $\mathrm{L}$. The sites at Granåsen, Sweden, Lat. $60^{\circ} 35^{\prime} \mathrm{N}$ Long. $15^{\circ} 30^{\prime} \mathrm{E}$, and Syktyvkar, Russia, Lat. $61^{\circ} 40^{\prime} \mathrm{N}$ Long. $50^{\circ} 50^{\prime} \mathrm{E}$, are oldgrowth forests with abundant amounts of substrate. The forests at Trun, Switzerland, Lat. $46^{\circ} 45^{\prime} \mathrm{N}$ Long. $8^{\circ} 59^{\prime} \mathrm{E}$, and Rietavas, Lithuania, Lat. $55^{\circ} 40^{\prime} \mathrm{N}$ Long. $22^{\circ} 00^{\prime} \mathrm{E}$, are managed for commercial production. At each site spores from 15 to 20 fruit-bodies, growing on Norway spruce wood, were sampled in an area less than $1 \mathrm{~km}^{2}$. This ensured that we would obtain spore isolates from 10-15 fruit-bodies because not all fruit-bodies could be expected to produce viable spores. Heterokaryotic mycelia were sampled from Trun.

\section{Isolation of spores and cultivation of isolates}

The isolates were sampled to represent genets of the fungus. We here define a functional genet as a heterokaryotic mycelium where sporocarps are formed. We sampled recombined spores from the sporocarp in order to deduce the genotype of the diploid by studying several haplotypes from each sporocarp.

Spores were sampled on glass plates that were placed under the sporocarp either directly in the field or in the laboratory. As we could not rule out the possibility of multiple fruiting in the same substrate, all sporocarps were sampled from separate logs to avoid resampling of the same genet. The spores were suspended in water and spread onto modified Hagem agar plates (Högberg et al., 1995). Between six and 15 germinated spores were individually transferred to new media to generate haploid homokaryotic single-spore cultures. Isolates were transferred to liquid Hagem media and grown at room temperature for 2-3 weeks prior to DNA extraction. Four single-spore isolates from each sporocarp were used for PCR-amplification. The isolates used in this study are listed in Table 1. In the Swiss population all isolates were heterokaryotic mycelia obtained from
Table 1 The isolates of Fomitopsis pinicola used in this study

\begin{tabular}{|c|c|c|}
\hline Isolate & Origin & Collector \\
\hline LiP16-1,2,4,5 & Rietavas, Lithuania & $\mathrm{JS} / \mathrm{RV}$ \\
\hline LiP9-1,3,4,5 & Rietavas, Lithuania & $\mathrm{JS} / \mathrm{RV}$ \\
\hline LiP18-1,2,4,5 & Rietavas, Lithuania & $\mathrm{JS} / \mathrm{RV}$ \\
\hline LiP19-1,2,3,4 & Rietavas, Lithuania & $\mathrm{JS} / \mathrm{RV}$ \\
\hline LiP17-1,2,3,5 & Rietavas, Lithuania & $\mathrm{JS} / \mathrm{RV}$ \\
\hline LiP11-2,3,4,5 & Rietavas, Lithuania & $\mathrm{JS} / \mathrm{RV}$ \\
\hline LiP1-1,3,4,5 & Rietavas, Lithuania & $\mathrm{JS} / \mathrm{RV}$ \\
\hline LiP23-1,3,4,5 & Rietavas, Lithuania & $\mathrm{JS} / \mathrm{RV}$ \\
\hline LiP2-1,2,4,5 & Rietavas, Lithuania & $\mathrm{JS} / \mathrm{RV}$ \\
\hline LiP21-1,2,3,4 & Rietavas, Lithuania & $\mathrm{JS} / \mathrm{RV}$ \\
\hline LiP14-1,3,4,5 & Rietavas, Lithuania & $\mathrm{JS} / \mathrm{RV}$ \\
\hline LiP15-1,2,3,4 & Rietavas, Lithuania & $\mathrm{JS} / \mathrm{RV}$ \\
\hline LiP3-1,2,3,4 & Rietavas, Lithuania & $\mathrm{JS} / \mathrm{RV}$ \\
\hline SyP1-a,b,c,f & Syktyvkar, Russia & $\mathrm{NH}$ \\
\hline SyP6-a,b,d,f & Syktyvkar, Russia & $\mathrm{NH}$ \\
\hline SyP4-b,LiP,e,f & Syktyvkar, Russia & $\mathrm{NH}$ \\
\hline SyP5-c,d,g,h & Syktyvkar, Russia & $\mathrm{NH}$ \\
\hline SyP3-b,LiP,d,e & Syktyvkar, Russia & NH \\
\hline SyP9-a,d,f,e & Syktyvkar, Russia & NH \\
\hline SyP7-a,c,d,e & Syktyvkar, Russia & NH \\
\hline SyP10-b,LiP,d,h & Syktyvkar, Russia & $\mathrm{NH}$ \\
\hline SyP13-c,d,f,h & Syktyvkar, Russia & $\mathrm{NH}$ \\
\hline SyP15-a,e,g,h & Syktyvkar, Russia & NH \\
\hline SyP14-a,b,d,e & Syktyvkar, Russia & $\mathrm{NH}$ \\
\hline SyP12-a,b,c,e & Syktyvkar, Russia & NH \\
\hline GrP1-2,3,4,5 & Granåsen, Sweden & NH \\
\hline GrP2-1,2,3,6 & Granåsen, Sweden & $\mathrm{NH}$ \\
\hline GrP4-1,4,5,7 & Granåsen, Sweden & $\mathrm{NH}$ \\
\hline GrP5-1,2,3,5 & Granåsen, Sweden & $\mathrm{NH}$ \\
\hline GrP7-2,3,4,5 & Granåsen, Sweden & $\mathrm{NH}$ \\
\hline GrP8-1,2,3,6 & Granåsen, Sweden & $\mathrm{NH}$ \\
\hline GrP9-1,2,3,4 & Granåsen, Sweden & $\mathrm{NH}$ \\
\hline GrP10-1,2,3,4 & Granåsen, Sweden & NH \\
\hline GrP13-1,3,5,7 & Granåsen, Sweden & $\mathrm{NH}$ \\
\hline GrP14-1,2,3,4 & Granåsen, Sweden & $\mathrm{NH}$ \\
\hline p11a & Trun, Switzerland & $\mathrm{BS} / \mathrm{OH}$ \\
\hline 12 & Trun, Switzerland & $\mathrm{BS} / \mathrm{OH}$ \\
\hline 21 & Trun, Switzerland & $\mathrm{BS} / \mathrm{OH}$ \\
\hline 30 & Trun, Switzerland & $\mathrm{BS} / \mathrm{OH}$ \\
\hline 40 & Trun, Switzerland & $\mathrm{BS} / \mathrm{OH}$ \\
\hline 41 & Trun, Switzerland & $\mathrm{BS} / \mathrm{OH}$ \\
\hline 42 & Trun, Switzerland & $\mathrm{BS} / \mathrm{OH}$ \\
\hline 43 & Trun, Switzerland & $\mathrm{BS} / \mathrm{OH}$ \\
\hline 51 & Trun, Switzerland & $\mathrm{BS} / \mathrm{OH}$ \\
\hline 61 & Trun, Switzerland & $\mathrm{BS} / \mathrm{OH}$ \\
\hline 68 & Trun, Switzerland & $\mathrm{BS} / \mathrm{OH}$ \\
\hline 81 & Trun, Switzerland & $\mathrm{BS} / \mathrm{OH}$ \\
\hline 90 & Trun, Switzerland & $\mathrm{BS} / \mathrm{OH}$ \\
\hline 91 & Trun, Switzerland & $\mathrm{BS} / \mathrm{OH}$ \\
\hline
\end{tabular}

JS, Jan Stenlid; RV, Rimvis Vasiliauskas; NH, Nils Högberg; BS, Benjamin Stöckling; OH, Ottmar Holdenrieder. All isolates are deposited at the Department of Forest Mycology \& Pathology, Swedish University of Agricultural Sciences, Uppsala, Sweden. 
the trama of sporocarps. For somatic incompatibility tests, isolates were inoculated pairwise, $3 \mathrm{~cm}$ apart, on the same malt agar plate. When grown together they either mingled or formed an incompatibility barrier. We used two inocula per plate, about $3 \mathrm{~cm}$ apart.

\section{DNA extraction and amplification}

The mycelia were lyophilized and extracted using a standard CTAB method (Högberg et al., 1995). Two primers were used. Four single-spore isolates from each fruit body were amplified with the primer 5'GAGGGTGGCGGTTCT-3' (the m13 core sequence) and the repetitive sequence $(\mathrm{CAGA})_{4}$ (Meyer et al., 1991). Reaction conditions were as follows: $10 \mathrm{~mm}$ Tris$\mathrm{HCl}$ ( $\mathrm{pH} 8.3$ ), $2.5 \mathrm{~mm} \mathrm{MgCl}_{2}, 200 \mathrm{~nm}$ of primer. We used the following thermocycle profile for amplification on a Perkin Elmer 480 thermocycler: initial denaturation at $94^{\circ} \mathrm{C}$ for $3 \mathrm{~min}$ followed by 35 cycles of $1 \mathrm{~min}$ denaturation at $94^{\circ} \mathrm{C}, 1 \mathrm{~min}$ annealing at $48^{\circ} \mathrm{C}$ and extension at $72^{\circ} \mathrm{C}$ for $1 \mathrm{~min}$. The extension step was prolonged $4 \mathrm{~s}$ for each cycle. After a final extension at $72^{\circ} \mathrm{C}$ for 10 min the samples were kept at $5^{\circ} \mathrm{C}$ until electrophoresis. Controls without template were included in all runs. All amplifications were also duplicated for verification of bands. The amplified DNA was separated by electrophoresis on $1.5 \%$ ME agarose (FMC-bioproducts). The DNA was stained in $0.5 \mathrm{mg} / \mathrm{L} \mathrm{EtBr}$ for $15 \mathrm{~min}$ and soaked in water for $15 \mathrm{~min}$, visualized over UV light and photographed. The gels were manually analysed for absence or presence of bands.

\section{Interpretation of bands and scoring of genotypes}

For the three populations, one each from Sweden, Lithuania and Russia where haploid single-spore isolates were used, the genotype of each heterokaryon was determined by combining the different banding patterns of four homokaryons. For each locus, the total presence or absence of a band among the four single-spore isolates from a sporocarp was interpreted as a homozygous individual, whereas polymorphism among the four isolates was interpreted as a heterozygote. The accuracy with which genotype frequencies can be estimated when using haplotype segregation analysis depends not only upon the number of genets included in the sample but also upon the probability of correctly identifying each genotype of each fungus. As the number of haploid single-spore cultures per genet is increased, the likelihood of a correct classification is increased, but so also is the amount of experimental effort required to classify each genotype. The same problem arises when estimating genotypes of conifers from the analysis of female gametophytes. For estimating heterozygosity Morris \& Spieth (1978) found that for most cases, the optimum sampling design is three female gametophytes per tree. In this study we have used four haploid single-spore cultures per genet, which would give an effective estimate of the heterozygosity in our sampling considering that we have studied two alleles per locus (Morris \& Spieth, 1978). In this way heterozygosity is underestimated by a maximum of $(1 / 2)^{3}$.

The frequency of heterozygotes in the Swiss population was estimated based on the assumption that it had reached a Hardy-Weinberg equilibrium. The unbiased estimator of the frequency for the null allele was used to estimate the frequency of this allele (Lynch \& Milligan, 1994). The frequency of heterozygotes was then estimated according to Hardy-Weinberg expectations.

For comparison with the results of the somatic incompatibility tests, similarity indices (Lynch, 1990) were calculated for the Swiss population by dividing the number of common bands by the total number of bands for the phenotypes.

\section{Genetical and statistical analysis}

Linkage disequilibrium was tested using $\chi^{2}$-tests for association in a global test for each pair of loci across all populations using the GENEPOP 1.2 program (Raymond \& Rousset, 1995). The segregation of the alleles was tested for each locus in a pooled sample that consisted of all haploid isolates from genets that were found to be heterozygous for the marker. $\chi^{2}$ ( 1 d.f.) was used to test possible deviations from a 1:1 ratio of alleles. The mean observed heterozygosity, as well as the expected heterozygosity for Hardy-Weinberg equilibrium, was calculated per locus for all samples as well as partitioned for the populations. Expected heterozygosity was calculated using Levene's (1949) correction for small samples. Unbiased estimates of the Hardy-Weinberg exact $P$-values for populations and loci with the associated standard errors were made by the Markov chain method under the null hypothesis of Hardy-Weinberg equilibrium (Guo \& Thompson, 1992) using the GENEPOP 1.2 program (Raymond \& Rousset, 1995). Wright's (1951) $F$-statistics were used to partition the genetic variation among the three populations from Sweden, Lithuania and Russia, respectively. The Swiss population was included in the analysis of the $F_{\mathrm{ST}}$ in a separate step because expected heterozygosity was calculated based on the frequency of the homozygote for the null allele in this population. Confidence intervals for the $F$-statistics were based on resampling by 15000 bootstrap replicates among loci and performed with the F-STAT program 
provided by J. Goudet, Université de Lausanne, Switzerland.

\section{Results}

The DNA amplification followed by electrophoresis resulted in 22 scorable bands, from which eight variable bands were used for further analysis. Five of these bands were amplified by the m-13 primer and three by the $(\mathrm{CAGA})_{4}$ primer. The chi-squared tests for association showed that two of the markers chosen were in linkage disequilibrium; one of these loci was excluded from the analysis and the remaining seven used as independent loci in the analysis (data not shown). Analysis of pooled samples of heterozygous individuals showed that the amplified band and the null allele of all loci segregated according to a pattern that would be expected for a $1: 1$ ratio (Table 2).

The observed heterozygosity calculated over seven loci was $0.40,0.38$ and 0.36 for the three populations from Lithuania, Russia and Sweden, respectively (Table 3), which did not differ significantly from the mean expected heterozygosity of $0.38,0.45$ and 0.37 for the same populations. All estimates of $F$-statistics indicated that the levels of inbreeding were near zero, within as well as between populations (Table 4), and none of the estimates had a $99 \%$ confidence interval that was different from zero. Because agreement between observed and expected heterozygosity was high in these three populations, we assume that this was also the case for the Swiss population. Thus we

Table 2 Segregation analysis for all loci

\begin{tabular}{lllc}
\hline Locus & Ratio & $\chi^{2}$ & $P$ \\
\hline $8(8)$ & $15: 17$ & 0.125 & 0.72 \\
$7(15)$ & $24: 36$ & 2.40 & 0.12 \\
$6(16)$ & $28: 36$ & 1.00 & 0.32 \\
$5(18)$ & $33: 39$ & 0.50 & 0.48 \\
$4(11)$ & $19: 25$ & 0.81 & 0.25 \\
$3(15)$ & $34: 26$ & 1.07 & 0.30 \\
$2(16)$ & $34: 30$ & 0.25 & 0.62 \\
$1(10)$ & $19: 21$ & 0.10 & 0.75 \\
\hline
\end{tabular}

$\chi^{2}$ values ( 1 d.f.) test the null hypothesis of 1:1 segregation of alleles.

Table 3 Observed and expected heterozygosities of the Fomitopsis pinicola populations

\begin{tabular}{|c|c|c|c|c|c|c|c|c|}
\hline \multirow[b]{2}{*}{ Population } & \multicolumn{7}{|c|}{ Locus } & \multirow[b]{2}{*}{ Exact $P$-value } \\
\hline & 1 & 2 & 3 & 4 & 5 & 6 & 7 & \\
\hline Lithuania observed & 0.39 & 0.39 & 0.31 & 0.46 & 0.62 & 0.39 & 0.23 & \\
\hline Lithuania & 0.41 & 0.41 & 0.27 & 0.44 & 0.44 & 0.51 & 0.21 & 0.67 SE. 0.004 \\
\hline Russia observed & 0.33 & 0.42 & 0.33 & 0.42 & 0.42 & 0.50 & 0.25 & \\
\hline Russia expected & 0.39 & 0.49 & 0.46 & 0.52 & 0.52 & 0.52 & 0.23 & 0.11 SE. 0.003 \\
\hline Sweden observed & 0.30 & 0.40 & 0.20 & 0.60 & 0.40 & 0.40 & 0.20 & \\
\hline Sweden expected & 0.27 & 0.50 & 0.19 & 0.51 & 0.44 & 0.50 & 0.19 & 0.46 SE. 0.006 \\
\hline Exact $P$-value & 0.48 & 0.27 & 0.49 & 0.59 & 0.65 & 0.17 & 1 & \\
\hline Standard error & 0.004 & 0.006 & 0.007 & 0.005 & 0.005 & 0.003 & 0.000 & \\
\hline
\end{tabular}

Unbiased estimates of the Hardy-Weinberg exact $P$-values for populations and loci with the associated standard errors were made by the Markov chain method under the null hypothesis of Hardy-Weinberg equilibrium (Guo \& Thompson, 1992).

Table 4 F-statistics for Fomitopsis pinicola

\begin{tabular}{|c|c|c|c|c|c|c|c|c|c|}
\hline & \multicolumn{7}{|c|}{ Locus } & \multirow[b]{2}{*}{ Overall } & \multirow{2}{*}{$\begin{array}{c}99 \% \\
\text { confidence } \\
\text { interval }\end{array}$} \\
\hline & 1 & 2 & 3 & 4 & 5 & 6 & 7 & & \\
\hline$F_{\mathrm{IS}}$ & 0.05 & 0.14 & 0.09 & 0 & -0.04 & 0.17 & -0.08 & 0.05 & $-0.02-0.12$ \\
\hline$F_{\mathrm{ST}}$ & -0.02 & -0.03 & 0.04 & -0.02 & 0.11 & -0.04 & -0.04 & 0 & $-0.04-0.07$ \\
\hline$F_{\mathrm{IT}}$ & 0.03 & 0.12 & 0.13 & -0.02 & 0.07 & 0.13 & -0.13 & 0.05 & $-0.02-0.13$ \\
\hline$F_{\mathrm{ST}}$ Switzerland & 0.07 & 0.08 & 0.04 & 0.06 & 0.02 & 0.04 & 0 & 0.04 & - \\
\hline
\end{tabular}

Confidence intervals are based on resampling by 15000 bootstrap replicates among loci. No confidence intervals are given for the Swiss population as the genotypes were inferred from phenotypes in that population.

(C) The Genetical Society of Great Britain, Heredity, 83, 354-360. 
Table 5 Somatic incompatibility tests and similarity indices for the Swiss isolates of Fomitopsis pinicola. -, incompatible; + , compatible. Details of the similarity index used are given in the text

\begin{tabular}{lcccccccccccccc}
\hline Isolate & $\mathrm{p} 11 \mathrm{a}$ & 12 & 21 & 30 & 40 & 41 & 42 & 43 & 51 & 61 & 68 & 81 & 90 & 91 \\
\hline 91 & $-/ 0.56$ & $-/ 0.67$ & $-/ 0.56$ & $-/ 0.33$ & $-/ 0.56$ & $-/ 0.56$ & $-/ 0.78$ & $-/ 0.56$ & $-/ 0.89$ & $-/ 0.67$ & $-/ 0.78$ & $-/ 0.56$ & $+/ 1$ & $+/ 1$ \\
90 & $-/ 0.56$ & $-/ 0.67$ & $-/ 0.56$ & $-/ 0.33$ & $-/ 0.56$ & $-/ 0.56$ & $-/ 0.78$ & $-/ 0.56$ & $-/ 0.89$ & $-/ 0.67$ & $-/ 0.78$ & $-/ 0.56$ & $+/ 1$ \\
81 & $-/ 0.78$ & $-/ 0.44$ & $-/ 0.56$ & $-/ 0.56$ & $-/ 0.56$ & $-/ 0.78$ & $-/ 0.33$ & $-/ 0.78$ & $-/ 0.44$ & $-/ 0.67$ & $-/ 0.78$ & $+/ 1$ & \\
68 & $-/ 0.78$ & $-/ 0.67$ & $-/ 0.56$ & $-/ 0.56$ & $-/ 0.78$ & $-/ 0.78$ & $-/ 0.78$ & $-/ 0.78$ & $-/ 0.67$ & $-/ 0.67$ & $+/ 1$ & & \\
61 & $-/ 0.44$ & $-/ 0.78$ & $-/ 0.89$ & $-/ 0.67$ & $-/ 0.44$ & $-/ 0.67$ & $-/ 0.44$ & $-/ 0.67$ & $-/ 0.56$ & $+/ 1$ & & & \\
51 & $-/ 0.44$ & $-/ 0.78$ & $-/ 0.44$ & $-/ 0.44$ & $-/ 0.44$ & $-/ 0.67$ & $-/ 0.67$ & $-/ 0.44$ & $+/ 1$ & & & & \\
43 & $-/ 0.56$ & $-/ 0.44$ & $-/ 0.56$ & $-/ 0.56$ & $-/ 0.78$ & $-/ 0.78$ & $-/ 0.56$ & $+/ 1$ & & & & & \\
42 & $-/ 0.56$ & $-/ 0.44$ & $-/ 0.56$ & $-/ 0.11$ & $-/ 0.56$ & $-/ 0.33$ & $+/ 1$ & & & & & & \\
41 & $-/ 0.55$ & $-/ 0.67$ & $-/ 0.56$ & $-/ 0.78$ & $-/ 0.56$ & $+/ 1$ & & & & & & & \\
40 & $-/ 0.56$ & $-/ 0.44$ & $-/ 0.33$ & $-/ 0.56$ & $+/ 1$ & & & & & & & & \\
30 & $-/ 0.33$ & $-/ 0.67$ & $-/ 0.56$ & $+/ 1$ & & & & & & & & & \\
21 & $-/ 0.56$ & $-/ 0.67$ & $+/ 1$ & & & & & & & & & &
\end{tabular}

inferred the expected heterozygosity from the frequency of homozygotes for the null allele. The expected heterozygote frequency calculated in this way was 0.41 for the Swiss population. The overall $F_{\mathrm{ST}}$ estimates were changed from 0 to 0.04 when the Swiss population was included (Table 4).

Incompatibility reactions were easily scored in this material. All isolates from the canopy gap in Switzerland tested by somatic incompatibility were found to belong to different individuals, except isolates 90 and 91 which were compatible (Table 5). Isolates 90 and 91 were obtained from the same substrate. The DNA fingerprint produced a congruent result, i.e. all isolates were distinguished by unique fingerprints except for the isolates 90 and 91. Similarity indices among the DNA fingerprints tested in the Swiss material are also shown in Table 5.

\section{Discussion}

This study confirms that $F$. pinicola is a fully outcrossing fungus with little differentiation among populations. The genetic diversity is high both on a local scale, such as after the founder event in the canopy gap in Switzerland, and at a regional scale for all populations, which implies high powers of dispersal among populations. The results agree well with earlier findings on a smaller geographical scale (Högberg et al., 1995). However, the $F_{\mathrm{ST}}$ values in this study are lower, probably owing to the larger sample size in this study which allowed values to be calculated with a higher degree of confidence. This is not a surprising result for a common fungus with a bipolar mating system, a broad ecological niche and a continuous supply of substrate (Ryvarden \& Gilbertsson, 1993). The diver- sity found in the Swiss population after disturbance in the form of a wind gap is also indicative both of the good dispersal capacity of this fungus and the presence of surrounding source populations, which produce abundant spores that can colonize newly created substrate patches in the landscape. The full agreement of the observed and expected heterozygosity that was found in this study also indicates that $F$. pinicola sampled on Norway spruce in Europe belong to one intersterility group. In North America two intersterility groups of $F$. pinicola have been reported (Mounce, 1929). However, an excess of heterozygotes in this material cannot be ruled out; because genotypes were inferred from four haploid single-spore cultures per genet, the heterozygosity could have been underestimated by $(1 / 2)^{3}$.

The same picture emerged when the genetic structure of two important root-infecting basidiomycetes was studied: Heterobasidion annosum (Stenlid et al., 1994) and Armillaria gallica (Saville et al., 1996). Nectria fuckeliana Both. and Cylindrobasidium evolvens (Fr.) Jül., two fungi that colonize stem wounds of $P$. abies, are two other examples of fungi that show little genetic differentiation over large geographical distances (Vasiliauskas \& Stenlid, 1997, 1998). All of the fungi mentioned above have heterothallic sexual systems that promote outcrossing and they can disperse long distances in the form of sexual spores. For Stereum sanguinolentum (Alb. et Schw.) Fr., a species with a mixed mating system and both homothallic and heterothallic sexual systems and several vegetative compatibility groups (Rayner \& Turton, 1982), genetic differentiation was detected within VC groups (Stenlid \& Vasiliauskas, 1998). In agricultural systems, pathogens such as Mycosphaerella graminicola (Fuckel) J. Schroder 
show little differentiation among populations, even over long distances (Boeger \& McDonald, 1993). Other examples of agricultural pathogens with little genetic differentiation among populations include Sclerotinia sclerotiorum (Lib.) de Barry parasitizing canola (Kohli \& Kohn, 1996). Sclerotinia sclerotiorum on Ranunculus ficaria L. and Melampsora lini (Ehrenb.) Lev. on wild populations of Linum marginale Cunn. are two examples where the patchy distribution of the host plant may restrict gene flow among populations (Burdon \& Jarosz, 1992; Kohli \& Kohn, 1996).

This study also shows that the AP-PCR method can be used for population genetic studies of fungi, where it is possible to isolate haploid single-spore isolates. When used in this way the method reveals the genotype rather than only the phenotype as when applied to diploid organisms. To reduce the probability of misclassification, the phenotypes of the heterokaryons could be scored as well, as only heterokaryons with bands could be heterozygotes. Scoring more single-spore isolates would also further reduce misclassification. As the frequency of heterozygotes agreed with Hardy-Weinberg expectations in the populations from Sweden, Russia and Lithuania, we calculated the expected heterozygosity from the unbiased estimator of the allele frequency given in Lynch \& Milligan (1994) in the Swiss population. We then found that the estimated expected heterozygosity was similar to the levels found in the other populations. This was also evident for locus seven with an expected heterozygosity of 0.2 . Otherwise, with a low frequency of the null allele in the population, it is possible that no homozygote will be detected and the heterozygotes missed. Accordingly we agree with Lynch \& Milligan's (1994) suggestion that the sample size should be increased 4-10 times when a diploid organism is studied by means of a dominant genetic marker compared to studies that utilize codominant markers. This increases the chances of detecting a possible homozygote if its frequency is low.

The congruency of somatic incompatibility tests and the phenotypes derived using AP-PCR found in this study agree with earlier comparisons between somatic incompatibility and individual delimitation made by means of similar genetic markers (Holmer et al., 1994; Guillaumin et al., 1996; Vasiliauskas \& Stenlid, 1997). Genetic variation within somatically compatible isolates has been interpreted as inbreeding in S. sanguinolentum (Stenlid \& Vasiliauskas, 1998). Also, a discrepancy between somatic incompatibility and RAPDs has been reported (Jacobson et al., 1993).

In conclusion, the gene pool of $F$. pinicola shows little or no differentiation even over large geographical distances. However, it is unlikely that spore dispersal commonly occurs over long distances (hundreds of kilometres).
Instead, it is more likely that the low genetic differentiation is mediated by the continuous linking of populations at both local and regional scales with instances of long-distance dispersal being the exception. Local population differentiation by random genetic drift is unlikely, given the large size of populations in this species.

\section{Acknowledgements}

Many thanks to Rimvis Vasiliauskas and Benjamin Stöckling for help with sampling the isolates from Rietavas and Trun, respectively, as well as to Karin Langenegger for excellent technical assistance. We are also grateful to Elna Stenström and Rimvis Vasiliauskas for comments on an earlier draft of this manuscript. This study was financed by the Oscar and Lilli Lamm Foundation and Carl Tryggers foundation. The field work in Lithuania and Russia was supported by the Swedish Royal Academy of Sciences.

\section{References}

BOEGER, J. M. AND McDONALD, B. 1993. Gene flow between geographic populations of Mycosphaerella graminicola (anamorph Septoria tritici) detected with restriction fragment length polymorphism markers. Phytopathology, 83, 11481154.

BURDON, J. J. AND JAROSZ, A. M. 1992. Temporal variation in the racial structure of flax rust (Melampsora lini) growing on natural stands of wild flax (Linum marginale): local versus metapopulation dynamics. Pl. Pathol., 41, 165-179.

GITZENDANNER, M. A., WHITE, E. E., FOORD, B. M., DUPPER, G. E., HODGKISS, P. D. AND KINLOCH, B. B., JR. 1996. Genetics of Cronartium ribicola: III. Mating system. Can. J. Bot., 74, 1852-1859.

GUILlAumin, J. J., ANDERSON, J. B., LEGRAND, P., GHAHARI, S. AND BERTHELAY, S. 1996. A comparison of different methods for the identification of genetics of Armillaria spp. New Phytol., 133, 333-344.

GuO, S. W. AND THOMPSON, E. A. 1992. Performing the exact test of Hardy-Weinberg proportions for multiple alleles. Biometrics, 48, 361-372.

HÖGBERG, N., STENLID, J. AND KARLSSON, J-O. 1995. Genetic differentiation in Fomitopsis pinicola (Swarts: Fr.) Karst studied by means of arbitrary primed-PCR. Mol. Ecol., 4, 675-680.

HOLMER, L., NITARE, L. AND STENLID, J. 1994. Population structure and decay pattern of Phellinus tremulae in Populus tremula as determined by somatic incompatibility. Can. J. Bot., 72, 1391-1396.

JACOBSON, K. M., MILlER, O. K., JR AND TURNER, B. J. 1993. Randomly amplified polymorphic DNA markers are superior to somatic incompatibility tests for discriminating genotypes in natural populations of the ectomycorrhizal fungus Suillus granulatus. Proc. Natl. Acad. Sci. U.S.A., 90, 9159-9163. 
KOHLI, Y. AND KOHN, L. M. 1996. Mitochondrial haplotypes in populations of Sclerotinia sclerotiorum: wide distribution in agriculture, local distribution in the wild. Mol. Ecol., 5, 773-783.

LEVENE, H. 1949. On a matching problem arising in genetics. Ann. Rev. Math. Stat., 20, 91-94.

LYNCH, M. 1990. Estimation of relatedness by DNA-fingerprinting Mol. Biol. Evol., 5, 584-599.

LYNCH, M. AND MILligAN, B. G. 1994. Analysis of population genetic structure with RAPD markers. Mol. Ecol., 3, 91-100.

MEYER, W., KOCH, A., NIEMANN, C., BEYERMANN, B., EPPLEN, J. T. AND BÖRNER, T. 1991. Differentiation among species and strains among filamentous fungi by DNA fingerprinting. Curr. Genet., 19, 239-242.

MORRIS, R. W. AND SPIETH, P. T. 1978. Sampling strategies for using female gametophytes to estimate heterozygosity in conifers. Theor. Appl. Genet, 51, 217-222.

MOUNCE, I. 1929. Studies in forest pathology. II. The biology of Fomes pinicola (Fr.) Cooke. Dominion. Can. Dept. Agric. Bull., III (N.S.), 56 pp.

MOUNCE, I. 1930. Notes on sexuality in Fomes pinicola (Fr.) Cooke, Fomes roseus (Fr.) Cooke, Polyporus tuckahoe (Gussow) Sacc. et Trott., P. Resinosus (Schrad.) Fr., P. Anceps Peck, Lenzites saeparia Fr., Trametes protracta Fr. and T. Suaveolens (L.) Fr. Proc. Can. Phyt. Soc., 1, 27-28.

RAYMOND, M. AND ROUSSET, F. 1995. GENEPOP (Version 1.2): Population genetics software for exact tests and ecumenicism. J. Hered., 86, 248-249.
RAYNER, A. D. M. AND TURTON, M. N. 1982. Mycelial interactions and population structure in the genus Stereum: S. rugosum. S. sanguinolentum and S. Rameale. Trans. Br. Mycol. Soc., 78, 483-493.

RyVArden, L. AND Gilbertsson, R. L. 1993. European Polypores. Synopsis fungorum 6. Fungiflora, Oslo, Norway.

SAVILle, J. S., YOELL, H. AND ANDERSSON, J. B. 1996. Genetic exchange and recombination in populations of the root infecting fungus Armillaria gallica. Mol. Ecol., 5, 485-497.

STENLID, J., KARLSSON, J-O. AND HÖGBERG, N. 1994. Intraspecific genetic variation in Heterobasidion annosum revealed by amplification of minisatellite DNA. Mycol. Res., 98, 57-63.

STENLID, J. AND VASILIAUSKAS, R. 1998. Genetic diversity within and among VC groups of Stereum sanguinolentum. Mol. Ecol., 7, 1265-1274.

VASILIAUSKAS, R. AND STENLID, J. 1997. Population structure and genetic variation in Nectria fuckeliana. Can. J. Bot., 75, 1707-1713.

VASILIAUSKAS, R. AND STENLID, J. 1998. Population structure and genetic variation in Cylindrobasidium evolvens. Mycol. Res., 102, 1453-1458.

WELSH, J. AND McLELlAND, M. 1990. Fingerprinting genomes using PCR with arbitrary primers. Nucl. Acids Res., 18, 6531-6535.

WORRALL, J. J. 1997. Somatic incompatibility in basidiomycetes. Mycologia, 89, 24-36.

Wright, S. 1951. The genetical structure of populations. Ann. Eugen., 15, 323-354. 